\title{
Short Connunication
}

\section{Mimickers of dermatophytes on $\mathrm{KOH}$ mount}

\author{
Richa Garg1,*, Sunil Gupta1, \\ ${ }^{1}$ Dept. of Dermatopathology, Sahu Rameshwar Saran Kothiwal Hospital and Research Centre, Moradabad, Uttar Pradesh, India
}

\section{A R T I C L E I N F O}

\section{Article history:}

Received 25-03-2020

Accepted 26-03-2020

Available online 21-04-2020

\section{Keywords:}

Mimickers

Dermatophytes

$\mathrm{KOH}$

Tinea.

\begin{abstract}
A B S T R A C T
The dermatophytes are a group of filamentous fungi that infect only superficial keratinized tissues of skin, hair and nails. $\mathrm{KOH}$ mount is an easy and rapid method to detect them. It is generally not difficult to make a diagnosis of dermatophytes on $\mathrm{KOH}$ based on typical characteristic appearance. However, sometimes the diagnosis becomes a challenge because of numerous normal structures which can be very similar to dermatophytes, especially when scrapings are taken from already treated modified tinea infection. This may lead to an erroneous diagnosis and inappropriate treatment of the patient with antifungal drugs which have their own side effects. In the present article, numerous mimickers of dermatophytes on $\mathrm{KOH}$ are described with the purpose of avoiding the potential diagnostic pitfalls.
\end{abstract}

(C) 2020 Published by Innovative Publication. This is an open access article under the CC BY-NC-ND license (https://creativecommons.org/licenses/by/4.0/)

\section{Introduction}

The dermatophytes are the fungi that reside exclusively on dead cornified layer of skin and skin appendages. The skin produces inflammatory and allergic response to them. ${ }^{1}$ Dermatophytes are divided into three generaTichophyton, Microsporum and Epidermophyton. Trichophyton infects hair, nails and skin, Microsporum infects skin and hair and Epidermatophyton infects skin and nails not hair. Infection by dermatophyets to smooth and non hairy skin of body is called Tinea corporis. Tinea unguium is the infection of nails, Tinea cruris involves groins and perineum, Tinea barbae affects face and neck, Tinea pedis affects foot and tinea capitis involves scalp. ${ }^{2,3}$ The species Trichophyton rubrum and Trichophyton glabrosa are more common than Microsporum and Epidermophyton species. ${ }^{4}$ The treatment with antifungal drugs commonly fluconazole, ketoconazole, itraconazole, griseofulvin and terbinafine depends on the site of infection and may vary from one week to months. As treatment with these drugs may cause side effects like elevation of liver enzymes, headache, nausea, gynaecomastia etc, their dose dependent therapy

\footnotetext{
* Corresponding author.

E-mail address: richag24@gmail.com (R. Garg).
}

should be optimized to the appropriate patient. ${ }^{5,6}$ The skin scraping method for $\mathrm{KOH}$ mount is used commonly by dermatologist for dermatophytes identification. ${ }^{7}$ The dermatologist and dermatopathologist should be aware of mimickers of dermatophytes for proper selection and treatment of the patient.

\subsection{Procedure}

The routine method involves skin scraping, potassium hydroxide (KOH) mount and microscopic examination. ${ }^{7}$

\subsubsection{Scraping}

The skin surface to be sampled is thoroughly cleaned using alcohol. Then, the surface is stretched with one hand and scrapings are taken along the edge of the lesion using 24G scalpel blade with other hand. On hairy surface, epilating short hair along with scrapping obtains a better yield. For nails, nail clippings may be taken or scraping the undersurface of involved dystrophic nail may be sampled. Scrapings are collected on glass slide and covered with another slide and sent to lab for $\mathrm{KOH}$ mount and microscopic examination. 


\subsubsection{KOH mount}

A drop of $10 \% \mathrm{KOH}$ is added on the slide with scrapings and covered by a cover slip made of fragile glass and gently heated to bring about clearing.

\subsubsection{Microscopic examination}

The slide is observed under direct microscope to find out spores and hypae by lowering down the condenser. The examination is done initially at low power (10X) and then at higher magnification (40X) to study the morphology of the fungus. Microscopy reveals branched septate hyphae with or without fungal spores. ${ }^{4}$

\section{Discussion}

The dermatophytes are a group of closely related filamentous fungi that infect only superficial keratinized tissues like skin, hair and nails. They cause Tinea or 'ringworm' infection on the body. 'Favus' is a chronic type of ringworm in which dense crust is developed in the hair follicles. Clinically, tinea may manifest as pruritis, blistering, fissures, spots and scales. ${ }^{1,8,9}$ In lesions, dermatophytes appear as septate hypae and arthospores. The three types of dermatophytes are of different shapes: Epidermophyton are club shaped, Microsporum are fusiform shaped and Trichophyton are cylinder shaped. ${ }^{4}$ The routine method of diagnosis is by examination of $\mathrm{KOH}$ mount of the skin scraping, however, species identification is possible only by culture examination. ${ }^{4}$ Usually, it is not difficult to identify dermatophytes on $\mathrm{KOH}$. However, sometimes the diagnosis becomes difficult as some normal structures mimic dermatophytes. ${ }^{7}$ This may cause erroneous diagnosis and inappropriate treatment by the treating clinician. The several mimickers of dermatophytes which may commonly encountered and their differentiating features are discussed below precisely.

\subsection{Cotton fibres/synthetic fibres}

Cotton fibres/synthetic fibres are the most common mimickers of the fungal hypae. ${ }^{7}$ They may be present due to cleaning of glass slides with either tissue papers,cotton or any other similar material. These fibres may even look branching along their length. However, they show no septation and are seen with taper ends (Figure 1 a). The true dermatophytes are always septate and their ends are not tapered (Figure 1b).

\subsection{Epidermal cells edges}

The epidermal polygonal cells edges commonly mimic dermatophytes ${ }^{7}$ due to refraction under the microscope when condenser is lowered down (Figure 2 a). They can be differentiated from dermatophytes as they don't show beaded appearance and branching which are seen in dermatophytes (Figure 2b).

\subsection{Broken hair shaft}

At low power, villous hair shaft can be mistaken for dermatophytes, however, they are always pigmented and and show no septation. They can also be differentiated from dermatophytes due to their broken ends (Figure 3 ).

\subsection{Gram negative bacteria}

Gram negative bacterial colonies may mimic dermatophytes belonging to the genera Trichophyton soleniecii (Favic chandelier) at low power. However, at high power, numerous small side branches can be traced out in true dermatophytes (Figure 4 a) which may not be seen in gram negative bacterial colonies (Figure 4b).

\subsection{Skin epithelial debris}

Epithelial debris from the skin scrapings may look fungal hypae under microscope (Figure 5). They may mimic Trichophyton rubrum. However, they give an impression of thick cast like appearance and are not branched. They may be avoided by thorough cleaning of the skin surface by alcohol before sampling.

\subsection{Seeping of $\mathrm{KOH}$ at edges}

Lastly, the seeping of $\mathrm{KOH}$ at the edges of coverslip along the imaginary lines may mimic to fungal hypae especially to Trichophyton mentagrophytes. It may happen due to overflow of $\mathrm{KOH}$ drop or improper placement of the glass coverslip This happens near or at the edges of coverslip and don't show true septation (Figure 6).

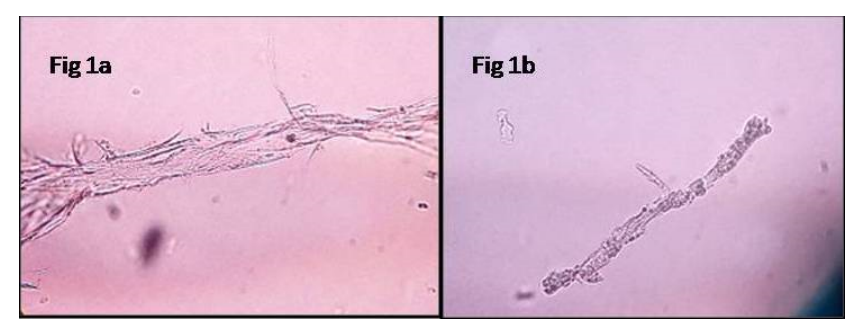

Fig. 1: KOH 40X (a) Cotton/syntheticfibres, (b) Dermatophytes showing septate hypae and branching.

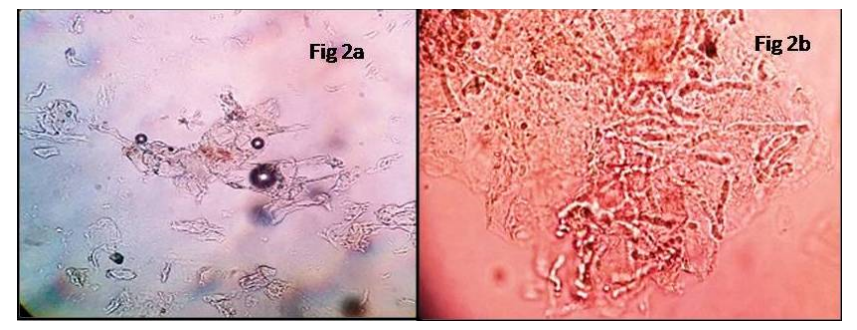

Fig. 2: $\mathrm{KOH} 40 \mathrm{X}$ (a)Refractile edges of polygonal epidermal cells, (b) Dermatophytes showing beaded appearance. 


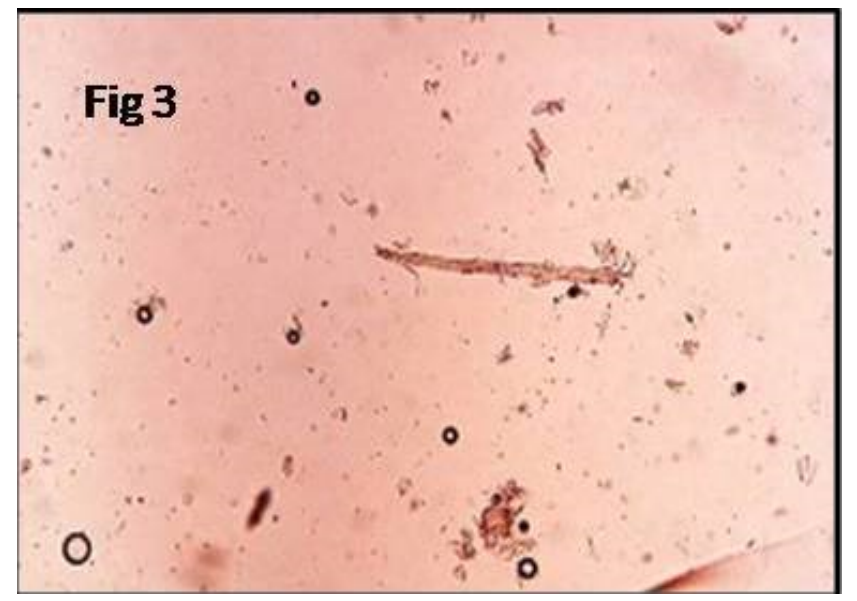

Fig. 3: KOH 20X Pigmented hair shaft with broken ends.

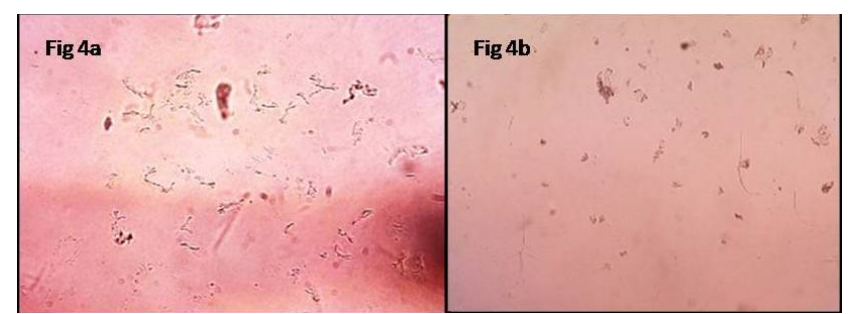

Fig. 4: KOH40X(a) Short branching fungal hypae, (b) Gram negative bacteria.

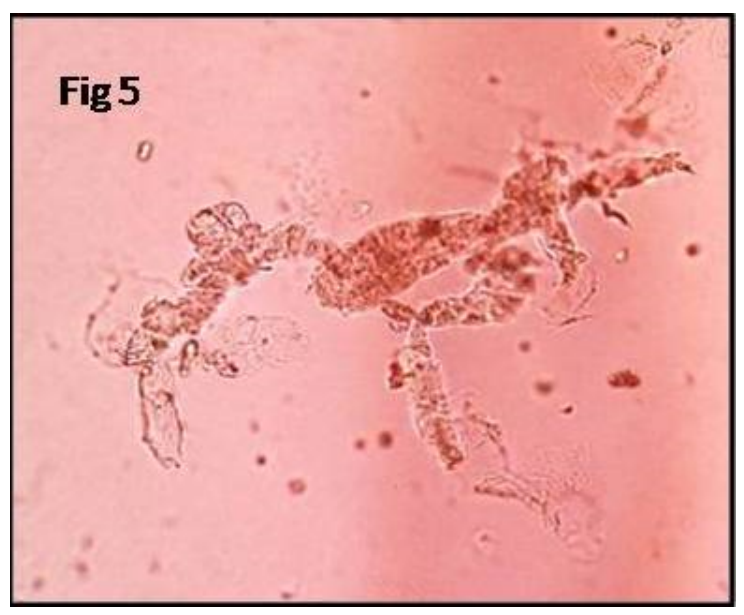

Fig. 5: $\mathrm{KOH} 40 \mathrm{X}$ Epithelial debri.

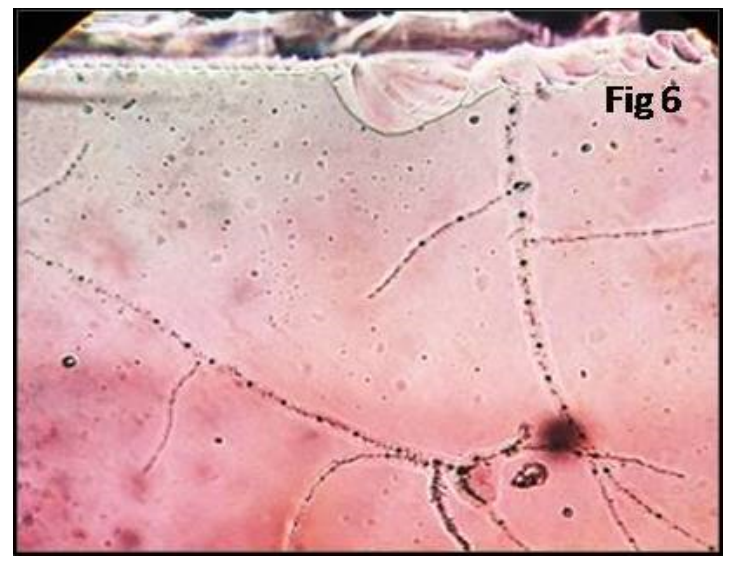

Fig. 6: $\mathrm{KOH} 40 \mathrm{X}$ Seeping of $\mathrm{KOH}$ along imaginary lines at an edge of cover slip.

\section{Conclusion}

$\mathrm{KOH}$ mount is a rapid and easy techinique to identify dermatophytes. However, some of normal structures may mimic dermatophytes on $\mathrm{KOH}$. It is therefore important to be aware of their existence and to recognize their differentiating features. It sometimes becomes a challenge to make a correct diagnosis especially in already treated or modified tinea infection. It is noteworthy that there are various morphological differences between true dermatophytes and its mimickers. Usually, the presence of features such as septation, branching and presence of spores establish the diagnosis of dermatophytes without any doubt. Few steps like cleaning of the skin surface with alcohol before sampling, avoidance of using cotton materials for wiping the slides, proper placement of $\mathrm{KOH}$ drops over the slide in addition to clinical correlation may help to reduce the mimickers and may prevent misdiagnosis so that inappropriate treatment with antifungal drugs to the patient who do not require them may be avoided. This article has been communicated to make dermatopathologist aware of the routinely encountered mimickers of dermatophytes. However, a detailed research work with statistical value to each mimicker needs to be done in future.

\section{Source of funding}

None.

\section{Conflicts of interest}

None.

\section{References}

1. Pires CAA, da Cruz NFS, Lobato AM, de Sousa PO, Carneiro FRO, et al. Clinical, epidemiological, and therapeutic profile of dermatophytosis. An Bras de Dermatol. 2014;89:259-264.

2. Goldstein A, Goldstein B. Dermatophyte (tinea) infections. UpToDate; 2020. Available from: https://www.uptodate.com/contents 
dermatophyte-tınea-infections.Accessedon20.

3. Hay R. Dermatophytosis (Ringworm) and Other Superficial Mycoses. In: JE B, R D, MJ B, editors. Mandell, Douglas, and Bennett's Principles and Practice of Infectious Diseases. Elsevier Saunders; 2015.

4. Paniker C, Editor. Ananthanarayan and Paniker's Textbook of microbiology. Orient Longman Publisher. 2006;p. 610-620.

5. Perkins J, Buckland M, Miler RA. Fungus among Us? Dermatophyte Infections, Mimickers, and Treatment Options.; 2020. Available from: https://www.reliasmedia.com/articles/141171-fungus-amongus-dermatophyte-infections-mimickers-and-treatment-options.

Accessedon22.

6. Tripathi KD, Editor. Essentials of Medical pharmacology. Jaypee Brothers Medical Publishers; 2014. p. 787-797.

7. Kurade S, Amladi S, Miskeen A. Skin scraping and a potassium hydroxide mount. Indian Journal of Dermatology, Venereology and Leprology. 2006;72(3):238-238. Available from: https://dx.do1.org/I0. $4103 / 0378-6323.25794$. 101:-10.4103/0378-6323.25794.
8. Khanna N, Editor. Dermatology and sexually transmitted diseases. Elsevier; 2017. p. 301-309.

9. Elmegeed SMA, Ouf SA, Moussa TAA, Eltahlawi SMR. Dermatophytes and other associated fungi in patients attending to some hospitals in Egypt. Braz J Microbiol. 2015;46(3):799-805.

\section{Author biography}

Richa Garg Consultant Pathologist

Sunil Gupta Consultant Ophthalmologist

Cite this article: Garg R, Gupta S. Mimickers of dermatophytes on KOH mount. IP Indian J Clin Exp Dermatol 2020;6(1):98-101. 